\title{
Assessment of solar radiation on diversely oriented surfaces and optimum tilts for solar absorbers in Malaysian tropical latitude
}

\author{
Khai Mun Ng • Nor Mariah Adam • \\ Othman Inayatullah $\cdot$ Mohd Zainal Abidin Ab. Kadir
}

Received: 28 September 2013/ Accepted: 20 December 2013/Published online: 12 March 2014

(C) The Author(s) 2014. This article is published with open access at Springerlink.com

\begin{abstract}
In this paper, the solar radiation on diversely oriented surfaces and optimum tilts for solar absorbers were assessed. The KT solar radiation model was coded in the MATLAB-based environment to compute the monthly solar radiation values. Seven-year data of monthly average daily solar radiation on a horizontal surface in Bangi, Malaysia (latitude $=3^{\circ} \mathrm{N}$ ) were adopted as input in the simulation programme and the results were compared with the local optimum tilt angle at solar noon and other solar radiation model. The contour mappings of solar irradiation at various orientations in 12 months were presented. Results showed that the surface tilted $\leq 20^{\circ}$ could intercept a relatively high solar intensity, which was less sensitive to the variation of azimuths with average solar insolation deviation of $11.82 \%$. The monthly optimum tilt angle
\end{abstract}

K. M. Ng $(\varangle) \cdot$ N. M. Adam · O. Inayatullah

Department of Mechanical and Manufacturing Engineering,

Faculty of Engineering, Universiti Putra Malaysia,

43400 UPM Serdang, Selangor, Malaysia

e-mail: mun_311@hotmail.com; ngkmun@iukl.edu.my

N. M. Adam

e-mail: mariah@upm.edu.my

O. Inayatullah

e-mail: othatiah@upm.edu.my

K. M. Ng

Department of Mechanical and Automotive Engineering, Faculty of Engineering and Technology Infrastructure, Infrastructure University Kuala Lumpur, Unipark Suria, Jalan Ikram-Uniten, 43000 Kajang, Selangor, Malaysia

\section{Z. A. Ab. Kadir}

Department of Electrical and Electronic Engineering, Faculty of Engineering, Universiti Putra Malaysia, 43400 UPM Serdang, Selangor, Malaysia e-mail: mzk@upm.edu.my altered throughout the year, ranging from $-24^{\circ}$ (in equator direction) to $+22^{\circ}$ (in north direction). The estimated annual optimum slope, $1.4^{\circ}$ facing to the equator, was close to local latitude. Based on the seasonal analysis, the northfacing surface was able to intercept higher daily average solar radiation energy compared to south-facing plane. The optimum angles for seasonal south- and north-facing surfaces were found to be $14.4^{\circ}$ and $14.8^{\circ}$, respectively, with a tolerable slope deviation of $\pm 5^{\circ}$ from the optimal values in the present work.

Keywords Solar radiation - Orientation - Tilt angle · Optimisation · Malaysia

\begin{tabular}{|c|c|}
\hline \multicolumn{2}{|c|}{ Abbreviations } \\
\hline$\delta$ & Declination angle \\
\hline num & Number of day of the year \\
\hline$\beta_{z, \text { noon }}$ & $\begin{array}{l}\text { Slope of the frontal surface of absorber at } \\
\text { noontime }\end{array}$ \\
\hline$\phi$ & Latitude angle \\
\hline$\theta$ & Angle of incidence of beam radiation \\
\hline$\beta$ & Slope \\
\hline$\gamma$ & Surface azimuth angle \\
\hline$\omega$ & Hour angle \\
\hline$\omega_{s}$ & Sunset hour angle \\
\hline$H_{o}$ & $\begin{array}{l}\text { Daily extraterrestrial radiation incident on a } \\
\text { horizontal surface }\end{array}$ \\
\hline $\bar{H}_{o}$ & $\begin{array}{l}\text { Monthly average daily extraterrestrial radiation } \\
\text { incident on a horizontal surface }\end{array}$ \\
\hline $\bar{H}_{T}$ & $\begin{array}{l}\text { Monthly average daily solar radiation on a tilted } \\
\text { surface }\end{array}$ \\
\hline$D$ & $\begin{array}{l}\text { Fraction of beam solar radiation on an inclined } \\
\text { surface to total radiation }\end{array}$ \\
\hline $\bar{H}_{d}$ & $\begin{array}{l}\text { Monthly average daily diffuse irradiation on } \\
\text { horizontal surface }\end{array}$ \\
\hline
\end{tabular}


$\rho_{g} \quad$ Ground reflectance factor

$\omega_{\text {sr }} \quad$ Sunrise hour angle

$G \quad$ Empirical function

$\bar{K}_{T} \quad$ Monthly average daily clearness index

\section{Introduction}

Solar energy is typically acknowledged as an important renewable energy source for the future in many countries. The knowledge of the irradiance level for a site is a prerequisite to any setup of solar power system. To maximise the interception of incident solar radiation energy, a solar absorber unit is positioned at the right orientation, which can be described in tilt and azimuth angles. In principle, the optimisation of the absorber orientation depends on the local latitude, climatic features and solar geometry.

In the aspect of the solar energy in building, it has been noticed that the ready-made collectors are normally installed on the roof surface following the existing surface orientation. Although building roof system has always been the location for placing solar energy unit, the confined space of roof surface with predetermined orientation and poor architectural uniformity revealed the limitation of optimisation [1, 2]. As triggered by the move of green concept, the model of building-integrated solar energy system attracts much attention presently, in which the integration has been carried out on various facades of buildings with diverse orientations such as wall, window, roof, gutter, balcony, awning and shutter. The scenario has extended the diversity of the orientation in which the investigation of solar energy source at various orientations has been accounted the primeval fundamental in evaluating the potential of solar energy systems in buildings.

To determine the radiation energy on a different orientation and its optimum value, one can perform solar radiation measurement at the site or employ a solar radiation model. The former practice is the most accurate, however, lack of complete meteorological information and constraint of having expensive measuring instruments at every location and orientation are the common issues related to solar process analysis. As a resolution, a number of techniques have been developed and improved to provide a satisfactory approximation for determining the behaviour of solar radiation energy.

Research works have been conducted to develop mathematical relations to assess the received solar radiation on sloped surfaces, in which the models of Liu and Jordan [3], Klein [4], Temps and Coulson [5], Klucher [6], Hay [7], Klein and Theilacker [8] and Perez et al. [9] are among the reference models. Due to the different treatment of sky diffuse component, the models can be ordinarily categorised into two major aspects known as isotropic and anisotropic models. Isotropic model assumes that the intensity of diffuse radiation is uniform over the entire sky dome. Meanwhile, the anisotropic model accounts either circumsolar diffuse, horizon brightening or both of them. The anisotropic sky approximation is typically suitable for clear skies; however, the isotropic model is more conservative and it performs well under the overcast skies [10].

A number of investigations have been carried out at different locations using various approaches to optimise the orientation of solar absorber for the maximum interception of solar radiation. Chow and Chan [11] performed numerical analysis and showed that the annual optimum value to be $45^{\circ}$ in azimuth sloped at local latitude $+2.8^{\circ}$ for the coastal region of South China. Elminir et al. [12] pointed that the Perez's model could accurately predict solar radiation hitting on a tilted surface at Helwan. Its annual optimum slope was about latitude $\pm 15^{\circ}$ for the winter and summer seasons, respectively. Yang and $\mathrm{Lu}$ [13] studied the optimum orientation of building-integrated photovoltaic (BIPV) claddings in Hong Kong by incorporating hourly clearness index into the anisotropic model. They found that the yearly optimum value for a southfacing solar absorber was slightly less than the local latitude. Pandey and Katiyar [14] expressed that the use of Klucher model was satisfactory to approximate the diffuse radiation on a sloped surface for the northern Indian region. A study by El-Sebaii et al. [15] indicated the isotropic model could provide a good estimate of horizontal diffuse radiation in Jeddah. They suggested the optimum slope to be latitude $+15^{\circ}$ for winter season and latitude $-15^{\circ}$ for summer season. Jafarkazemi and Saadabadi [16] applied the KT method to assess the consequence of orientation on the optimum setting of solar collectors. They reported the annual optimum tilt angle for Abu Dhabi was $2.4^{\circ}$ deviated from its latitude. A study of optimum tilt angle for solar collectors in Iran was carried out using an empirical approach and the results showed that the optimum tilt angle was lower for a place with a low clearness index despite the same latitude [17]. Yadav and Chandel [18] discussed various solar radiation models on tilted surfaces and optimisation techniques.

Besides the conventional solar modelling methods, the optimisation exercise can be done using other techniques such as genetic algorithm (GA), simulated annealing (SA), particle swarm optimisation (PSO) and artificial neural network (ANN), in which the methods are proper for the estimation dealing with complex non-linear variables. Celik and Muneer [19] used the generalised regression type of neural network to determine the solar irradiation on a tilted surface which had presented a good accuracy with $R^{2}$ value (coefficient of determination) of 0.987 . Khatib et al. [20] 
compared linear, non-linear and ANN models to predict the diffuse radiation in Malaysia and indicated that the ANN could generate better estimate. Talebizadeh et al. [21] used GA and KT methods to determine the optimum orientation of a solar absorber. They noted the optimum tilt angles were more sensitive to direct solar radiation. Behrang et al. [22] applied PSO technique to enhance the estimation of monthly average daily global solar radiation on horizontal surface. Chen et al. [23] presented the optimal angle of the fixed solar panels situated in Taiwan using the GA and SA optimisation techniques.

With the geographic coordinates of about $0^{\circ} 51^{\prime}$ to $6^{\circ} 43^{\prime}$ $\mathrm{N}$ in latitude $(\phi)$ and $99^{\circ} 38^{\prime}$ to $119^{\circ} 16^{\prime} \mathrm{E}$ in longitude, Malaysia is situated within the equatorial zone possessing hot humid tropical monsoon climates with plenty supply of solar radiation. The solar insolation on ground is about $400-600 \mathrm{MJ} / \mathrm{m}^{2}$ monthly or $4-5 \mathrm{kWh} / \mathrm{m}^{2}$ per day with average sunshine duration of 4-8 h [24]. The figures have shown the amount of this natural energy reaching on an outdoor-exposed object is abundant. Due to this fact, Malaysia is commonly recognised by researchers as a potential nation to promote solar energy technology.

Many researchers have examined the solar radiation in the country [20, 25-37], in brief, the previous works were carried out using various techniques to analyse and measure the solar intensity and solar behaviour without concerning the orientation factor in specific. The investigation of the solar intensity at different azimuth and tilt angles is very few in the equatorial tropics despite of its attractive potential. Most studies [16, 21] were reported at the middle and high latitudes that might not be applicable in the context of low latitude regions featuring the relatively less seasonal variation. In Malaysia, a few articles have presented interest in the orientation aspect. Bari [38] estimated the optimum slope of solar collector for certain periods of operation to propose an optimal slope for seasonal solar applications. Another study [39] was to deal with the optimum slope of a hot water system. In other low latitude regions, Yakup and Malik [40] estimated the optimum orientation of solar collector in Brunei. They proposed to alter the optimum tilt angle twelve times annually in which the output was quantitatively comparable to the daily changing optimum tilt angle. Cronemberger et al. [41] evaluated the received solar radiation intensity on various surfaces of Brazilian building for photovoltaic application at latitudes between $0^{\circ}$ and $30^{\circ} \mathrm{S}$. They indicated the optimum value could be up to $9^{\circ}$ above the latitude. Idowu et al. [42] proposed monthly optimised tilt angles for the performance enhancement of solar heating systems in Nigeria. The suggested tilt angles ranging between $\phi \pm 25^{\circ}$.

In the "rule of thumb", the south-facing surface offers better solar irradiance energy collection for the regions placed in northern hemisphere, and vice versa [43-47].
This is true at the medium and high latitudes, in which the sun tends to the south or north sky of the site for a longer period. In the region of low latitude, however, the scenario may be dissimilar. The sun tilts to both south and north skies of the site with a more uniform period in 1 year. Therefore, for the low latitude, despite of its location at northern hemisphere, the north-oriented surface can potentially intercept a prominent amount of solar irradiance. It leads to a rational hypothesis that the north-facing components can receive a reasonable amount of radiation energy. Optimum tilt angle is expected to be positioned facing to north for seasonal optimum energy collection.

In the present work, the monthly average daily global radiations on surfaces at various azimuth and tilt angles throughout 1 year were analysed for Bangi, Malaysia (located at latitude of $3^{\circ} \mathrm{N}$ ). The seven-year historical data of monthly average daily radiation on a horizontal surface, $\bar{H}$, measured at Bangi [28] were used as a representative input data in the computation, in which it has reflected the localised patterns and long-term records of solar radiation. The radiation values on surfaces sloped towards the equator and North Pole were presented to verify the hypothesis. Then, the optimal tilt angle was estimated in annual and seasonal bases. In the study, the algorithm of KT solar radiation model was developed in the MATLAB simulation platform. The model was chosen as it enabled the determination of solar irradiation for all surface orientations with good estimation. Besides, this method is appropriate for an interested location where the $\bar{H}$ is the only available solar radiation data at the site. The same method has been adopted in several studies recently [16, $21,48]$. In this paper, the solar insolation at various orientations under the Malaysian tropical climates was assessed to serve as a reference for the solar application in buildings.

\section{Methods}

Modelling of solar geometry

The apparent position of the sun relative to the plane on the ground is dynamic depending on several geometric parameters. According to [49], the declination angle $\delta$ can be determined from equation:

$\delta=23.45 \sin (360 \times(284+$ num $) / 365)$

where num is the number of day of the year in Julian calendar, $1 \leq$ num $\leq 365$, starting from 1 st January. For a solar absorber in the northern hemisphere, if its frontal surface is intended to be positioned normally to the incident ray during solar noontime to intercept the solar radiation maximally, the slope of the absorber is: 
$\beta_{z, \text { noon }}=|\phi-\delta|$

where $\beta_{z \text {,noon }}$ is the slope of the frontal surface of absorber at noontime and $\phi$ is the latitude angle of location with north positive, equator zero and south negative. The general relationship among the parameters of declination, latitude, slope, surface azimuth angle, hour angle and the angle of incidence of beam radiation is defined as below [10]:

$$
\begin{aligned}
& \cos \theta=\sin \delta \sin \phi \cos \beta-\sin \delta \cos \phi \sin \beta \cos \gamma \\
& \quad+\cos \delta \cos \phi \cos \beta \cos \omega+\cos \delta \sin \phi \sin \beta \cos \gamma \cos \omega \\
& \quad+\cos \delta \sin \beta \sin \gamma \sin \omega
\end{aligned}
$$

where $\theta$ is the angle of incidence of beam radiation, $\beta$ is the slope, $\gamma$ is the surface azimuth angle (measured at zero due south, west positive and east negative) and $\omega$ is the hour angle $\left(15^{\circ}\right.$ per hour displaced from local meridian; morning negative, afternoon positive). Below are the limitations of using the Eq. (3):

1. The angle of incidence of beam radiation is $0^{\circ} \leq \theta<$ $90^{\circ}$. Any angle $\theta \geq 90^{\circ}$ means the beam radiation does not reach the frontal surface of the absorber.

2. The hour angle is between sunrise and sunset only.

3. The slope $\beta>90^{\circ}$ indicates that the surface is facing downward.

The sunset hour angle $\omega_{s}$ is given by:

$$
\begin{aligned}
\omega_{s} & =\cos ^{-1}[-(\sin \phi \sin \delta) /(\cos \phi \cos \delta)] \\
& =\cos ^{-1}[-\tan \phi \tan \delta]
\end{aligned}
$$

The sunrise hour angle is termed as $-\omega_{s}$. The $\pm \omega_{s}$ is the boundary of hour angle at a location. The daily extraterrestrial radiation incident on a horizontal surface can be calculated by applying equation:

$$
\begin{gathered}
H_{o}=(24 \times 3600 / \pi) G_{\mathrm{sc}}(1+0.033 \cos (360 \mathrm{num} / 365)) \\
\left(\left(\pi \omega_{s} / 180\right) \sin \delta \sin \phi+\cos \delta \cos \phi \sin \omega_{s}\right)
\end{gathered}
$$

Refer to Eq. (5), the monthly average daily extraterrestrial radiation incident on a horizontal surface, $\bar{H}_{o}$ can be determined using the number of day and declination angle for the mean day of the month [10].

Modelling of solar irradiation on inclined surfaces

An isotropic model, KT method [8], was employed to determine the total solar radiation reaching on a sloped surface at various orientations. The method assumes the diffuse and ground-reflected radiation streams are both isotropic. According to [10] and [18], this model had shown enhanced results over the isotropic model when checked with hourly calculation based on long-term period of radiation data. According to the KT model, the total monthly average daily solar radiation incident on a tilted surface, $\bar{H}_{T}$, is defined as:

$\bar{H}_{T}=\bar{H} \bar{R}$

The term $\bar{R}$ is formulated as the sum of three radiation components known as beam, diffuse and ground-reflected radiations incident on the tilted surface. The method assumes that the surface is unshaded and the boundary of solar hour angle is based on mean day of each month. The $\bar{R}$ is defined as $[8,10]$ :

$\bar{R}=D+\left\{\bar{H}_{d} / \bar{H} \times(1+\cos \beta) / 2\right\}+\left\{\rho_{g}(1-\cos \beta) / 2\right\}$

where $D$ is the fraction of beam solar radiation on an inclined surface to total radiation, $\bar{H}_{d}$ is the monthly average daily diffuse irradiation on horizontal surface and $\rho_{g}$ is the ground reflectance factor. In this work, the value of $\rho_{g}$ is assumed to be $0.2[16,41,50,51]$ for all months and locations due to the Malaysian weather of having less climatic changes and no snow cover throughout a year. The value is ordinarily satisfactory and accepted in most of the engineering practices as reported by other research works. The $D$ is given as [8]:

$D= \begin{cases}\max \left(0, G\left(\omega_{\mathrm{ss}}, \omega_{\mathrm{sr}}\right)\right) & \text { if } \omega_{\mathrm{ss}} \geq \omega_{\mathrm{sr}} \\ \max \left(0,\left[G\left(\omega_{\mathrm{ss}},-\omega_{s}\right)+G\left(\omega_{s}, \omega_{\mathrm{sr}}\right)\right]\right) & \text { if } \omega_{\mathrm{ss}}<\omega_{\mathrm{sr}}\end{cases}$

where $\omega_{\mathrm{ss}}$ and $\omega_{\mathrm{sr}}$ are the sunset and sunrise hour angles for beam radiation on an inclined surface. Depending on the surface orientation and solar geometry, the signs of $\omega_{\mathrm{ss}}$ and $\omega_{\text {sr }}$ might be affected as described in the equations below [8]:

$\left|\omega_{\mathrm{sr}}\right|=\min \left[\omega_{s}, \cos ^{-1}\left(\frac{A B+C \sqrt{A^{2}-B^{2}+C^{2}}}{A^{2}+C^{2}}\right)\right]$

$\omega_{\mathrm{sr}}= \begin{cases}-\left|\omega_{\mathrm{sr}}\right| & \text { if }(A>0 \text { and } B>0) \text { or }(A \geq B) \\ +\left|\omega_{\mathrm{sr}}\right| & \text { otherwise }\end{cases}$

$\left|\omega_{\mathrm{ss}}\right|=\min \left[\omega_{s}, \cos ^{-1}\left(\frac{A B-C \sqrt{A^{2}-B^{2}+C^{2}}}{A^{2}+C^{2}}\right)\right]$

$\omega_{\mathrm{ss}}= \begin{cases}+\left|\omega_{\mathrm{ss}}\right| & \text { if }(A>0 \text { and } B>0) \text { or }(A \geq B) \\ -\left|\omega_{\mathrm{ss}}\right| & \text { otherwise }\end{cases}$

With

$A=\cos \beta+\tan \phi \cos \gamma \sin \beta$

$B=\cos \omega_{s} \cos \beta+\tan \delta \sin \beta \cos \gamma$

$C=\left(\begin{array}{ll}\sin \beta & \sin \gamma\end{array}\right) / \cos \phi$

In Eqs. (9) and (10), the value within the square root can be negative under certain specific orientation corresponding to the sun path. It is caused by the position of the 
Fig. 1 Algorithm flow of solar radiation model

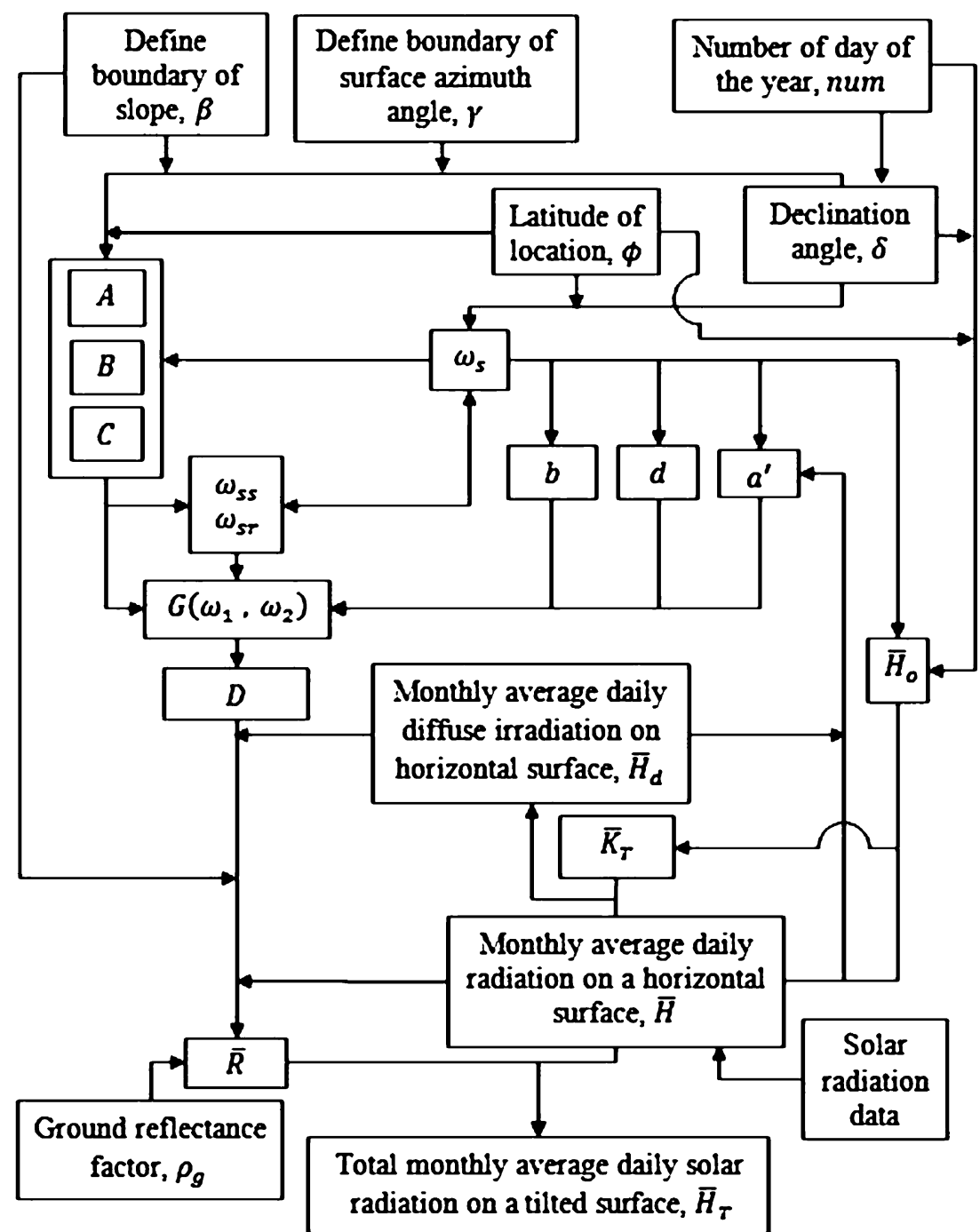

surface orientation that the solar incidence angle is $<90^{\circ}$ of sunrise or $>90^{\circ}$ of sunset at all times. In the present work, a boundary has been set to deal with this limitation of mathematic formulation, in which $\omega_{\mathrm{sr}}$ and $\omega_{\mathrm{ss}}$ are set to $-\omega_{s}$ and $+\omega_{s}$, respectively. The terms "max" and "min" mean the larger and smaller of the two items in the brackets, correspondingly. After defining the boundary of solar hour angle, the empirical function $G$ can be solved in the equation below:

$$
\begin{aligned}
& G\left(\omega_{1}, \omega_{2}\right)=[1 /(2 d)]\left[\left((b A / 2)-a^{\prime} B\right)\left(\omega_{1}-\omega_{2}\right)(\pi / 180)\right. \\
& \quad+\left(a^{\prime} A-b B\right)\left(\sin \omega_{1}-\sin \omega_{2}\right)-a^{\prime} C\left(\cos \omega_{1}-\cos \omega_{2}\right) \\
& \quad+(b A / 2)\left(\sin \omega_{1} \cos \omega_{1}-\sin \omega_{2} \cos \omega_{2}\right) \\
& \left.\quad+(b C / 2)\left(\sin ^{2} \omega_{1}-\sin ^{2} \omega_{2}\right)\right]
\end{aligned}
$$

The $\omega_{1}$ and $\omega_{2}$ correspond to $\omega_{\mathrm{ss}}, \omega_{\mathrm{sr}}$ and $\omega_{s}$ accordingly as presented in Eqs. (8)-(10). Meanwhile, the empirical coefficients $a^{\prime}, b$ and $d$ are as follows: $a^{\prime}=\left[0.4090+0.5016 \sin \left(\omega_{s}-60\right)\right]-\left(\bar{H}_{d} / \bar{H}\right)$

$b=0.6609-0.4767 \sin \left(\omega_{s}-60\right)$

$d=\sin \omega_{s}-\left(\left(\pi \omega_{s} / 180\right) \cos \omega_{s}\right)$

To solve the $\bar{H}_{d}$, the Erbs et al. [52] model was applied. For $\omega_{s} \leq 81.4^{\circ}$ and $0.3 \leq \bar{K}_{T} \leq 0.8$,

$\bar{H}_{d} / \bar{H}=1.391-3.560 \bar{K}_{T}+4.189 \bar{K}_{T}^{2}-2.137 \bar{K}_{T}^{3}$

And for $\omega_{s}>81.4^{\circ}$ and $0.3 \leq \bar{K}_{T} \leq 0.8$,

$\bar{H}_{d} / \bar{H}=1.311-3.022 \bar{K}_{T}+3.427 \bar{K}_{T}^{2}-1.821 \bar{K}_{T}^{3}$

where $\bar{K}_{T}$ is the monthly average daily clearness index, which can be calculated using the general relation as below [10]:

$\bar{K}_{T}=\bar{H} / \bar{H}_{o}$

A complete algorithm flow of absorber orientation-solar radiation interception model is presented in Fig. 1. The 
azimuth and slope angles undertaken were $-180^{\circ}$ to $+180^{\circ}$ and $0^{\circ}$ to $90^{\circ}$, respectively.

The presented algorithm was developed with the simplification that a façade is an absorber like other standard solar collector without obstacles around. This is valid if the unit is placed at the top side of the building. Nevertheless, a solar absorbing façade located below the building top roof at one side might not receive the incident solar radiation coming from the back of the building. To accommodate this boundary, the present work considers that the absorber is facing the two cardinal orientations, due south and north. This suggests that the interception of incident sunray by the absorber on building is in seasonal manner as it relies on the yearly sun trajectory in either northern or southern sky of the site. In the point of view of local climatical features, therefore, the investigation of optimal position of solar absorber was performed in seasonal basis to maximise the interception of solar radiation energy. In the evaluation of seasonal optimum tilt angle, the calendar year was divided into two seasons: southern exposure season and northern exposure season in corresponding to the placement of absorber surface orientation on building. The seasonal average daily solar irradiation was then evaluated and the optimal tilt angle could be resolved mathematically using the method of $(d y / d x=0)$. It should be noted that the seasonal assessment for eastern and western exposure surfaces was not covered in the present work.

\section{Results and discussion}

Solar position in the north-south axis orientation

Based on the formulation and the algorithm flow presented above, a MATLAB code was developed to compute the solar irradiation on various surface orientations at Bangi, Malaysia $\left(\phi=3^{\circ}\right)$. Figure 2 shows the slope of an absorber surface to face normally to the sun at solar noon for a complete calendar year. It indicated the daily sun position in the north-south axis orientation to suggest the optimum tilt angles at solar noon. The positive value depicted that the surface was inclined towards the North Pole, whereas the negative value meant the surface was inclined towards the equator. The slopes were within the range of $-26.45^{\circ}$ to $+20.45^{\circ}$.

From the result, the sun ray reaching on the surface facing to the north starting from 30 March till 13 September; meanwhile for the remaining dates, the sun tends to the south sky. The surface facing to north was exposed to the sun for 168 days, which was equivalent to about $46 \%$ of total days in 1 year. The opposite side accounted for $54 \%$ with a total of 197 days. Due to the proximity to the equator, although the south-facing surface reported a longer period of solar radiation exposure; the north-facing component has covered a noticeable range of period with quite uniform yearly solar trajectory which was dissimilar to the high latitude regions.

Figure 3 presents the simulated extraterrestrial radiation intensity at the site. It shows the upper limit of the incoming solar radiation on a horizontal plane in daily and monthly bases without the concern of atmospheric influences. The inclination of the earth and latitude of the site has affected the trend of the radiation level with values ranging approximately from 34.2 to $37.8 \mathrm{MJ} / \mathrm{m}^{2}$.

\section{Solar radiation on diversely oriented surfaces}

With the adoption of the long-term measured radiation data and widely recognised solar radiation model, the intensity of the total monthly average daily solar irradiation on diversely oriented surfaces at the site was simulated for 12 months. Figures 4 and 5 present the contour mappings of received monthly average daily solar radiation on surfaces for various azimuth angles and tilt angles from January to December. Results were simulated in the same range of solar radiation level to ease the comparison visually. The mappings showed a considerably large variation of solar radiation intensity on surfaces at different orientations and tilt angles. In general, the radiation pattern followed the monthly apparent position of the sun, in which the high quantity of solar radiation intensity shifted from $0^{\circ}$ azimuth (south facing) to $\pm 180^{\circ}$ azimuth (north facing) and returned to $0^{\circ}$ azimuth.

The months of March and September were the interfaces for the transition. This was consistent with the curve profile in Fig. 2 in which the sun apparent position has moved from east to west with almost null zenith angle at local solar noon during 29-30 March and 13-14 September. It caused the solar intensity distribution is relatively uniform across the azimuth angles for a tilt angle.

One can notice that the surface with low tilt angles, below $20^{\circ}$, could intercept a relatively high intensity of average daily solar radiation in every month averagely through a year. This information is imperative for passive and active solar energy systems. The results revealed that the surfaces with horizontal placement and small angle of inclination could potentially give a good yield in solar energy collection. In contrast, those types of orientations should be avoided if the surfaces disfavour overheating, especially for passive elements. For the orientation with high inclination, the quantity of solar irradiation was lower showing the opposite pattern to the low inclination angle. When the high solar radiation intensity was available at small tilt angle at $0^{\circ}$ azimuth, low solar radiation intensity was observed at large tilt angle at $180^{\circ}$ azimuth, and vice versa. 
Fig. 2 Slope of absorber surface normal to the sunrays at solar noon
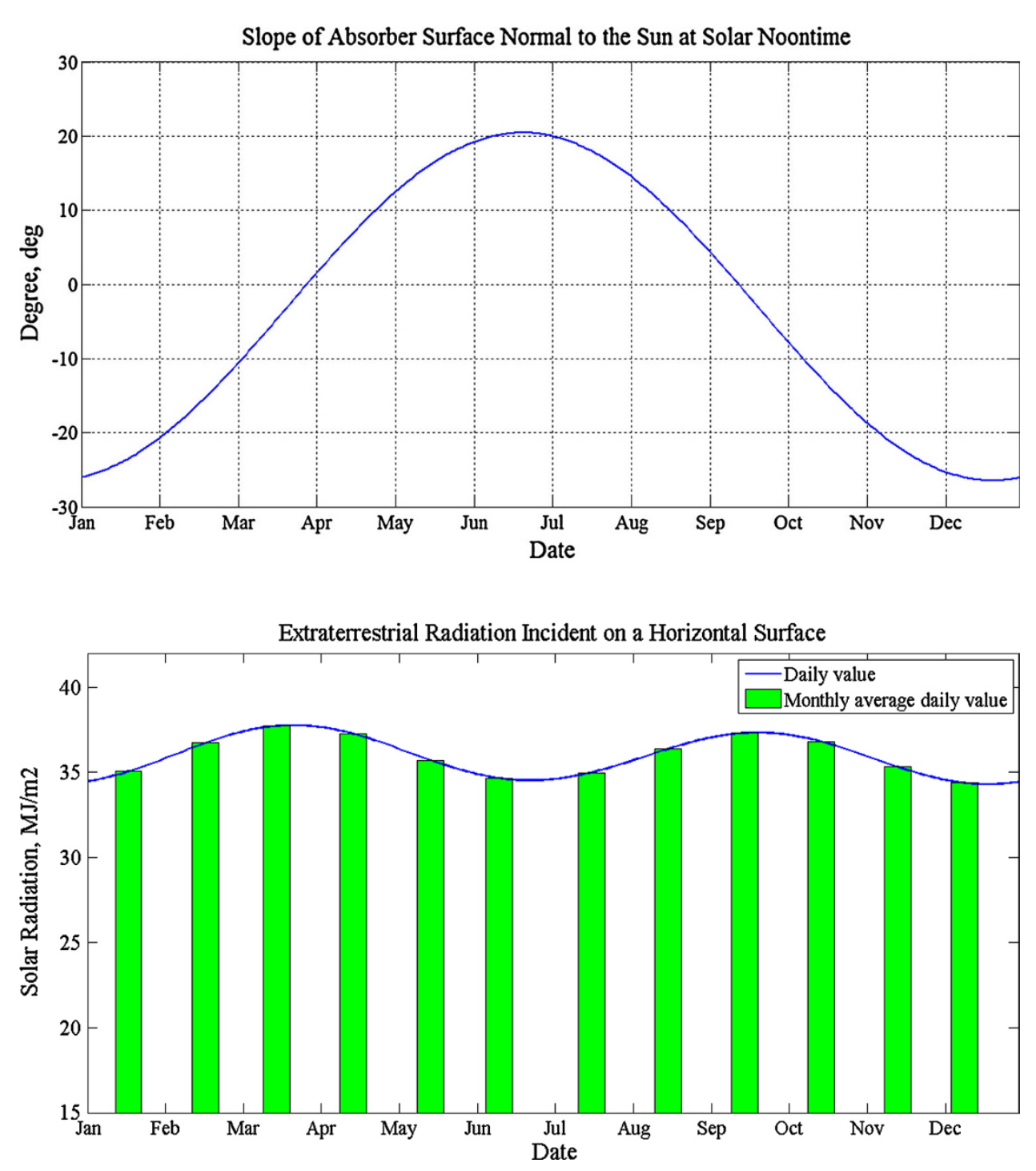

Fig. 3 Daily and monthly average daily extraterrestrial radiation incident on a horizontal surface at the latitude of $3^{\circ} \mathrm{N}$
The computed average percentage deviations of the lowest insolation from the highest insolation for $0^{\circ} \leq \beta \leq 20^{\circ}$ and $70^{\circ} \leq \beta \leq 90^{\circ}$ across all the azimuths in 12 months were 11.82 and $51.27 \%$, respectively. It pointed that a low tilt angle was relatively insensitive to the variation of azimuth angle as compared to a high tilt angle. This was in agreement with the result of [39]. According to the results, the attempt to attach a solar absorber on a vertical wall or any high sloped surface was a secondary choice at the low latitude region. These graphical results could be helpful for designers or engineers in the design stage of dealing with the use of solar absorber in building.

Solar radiation on south- and north-oriented surfaces

This is to note that the solar absorber on building might face to a certain predefined azimuth. In this work, the received monthly average daily solar radiation on south- facing (towards the equator) and north-facing surfaces was simulated in $10^{\circ}$ step of tilt angle for 12 months. Figures 6 and 7 depict the results. It was noticed that a surface with tilt angles up to $30^{\circ}$ could intercept a comparatively high amount of solar radiation energy for each month in both directional facings. For the equator-facing surface, the three highest values of solar irradiation were discovered on July $0^{\circ}$ slope, February $10^{\circ}$ and $20^{\circ}$ slopes with radiation intensities of $16.62,16.21$ and $16.24 \mathrm{MJ} / \mathrm{m}^{2}$, respectively. For the north-facing surface, the three highest figures were found on the same month of July at $10^{\circ}, 20^{\circ}$ and $30^{\circ}$ with values of $17.21,17.43$ and $17.29 \mathrm{MJ} / \mathrm{m}^{2}$, respectively. In the month of February, a south-facing surface was exposed to solar irradiation of over $15.34 \mathrm{MJ} / \mathrm{m}^{2}$ with the biggest range of tilt angles up to $40^{\circ}$. For a north-facing surface, the similar biggest range of tilt angles could be detected in the month of July with solar irradiation of more than $16.79 \mathrm{MJ} / \mathrm{m}^{2}$. It implied that south-facing absorber could 

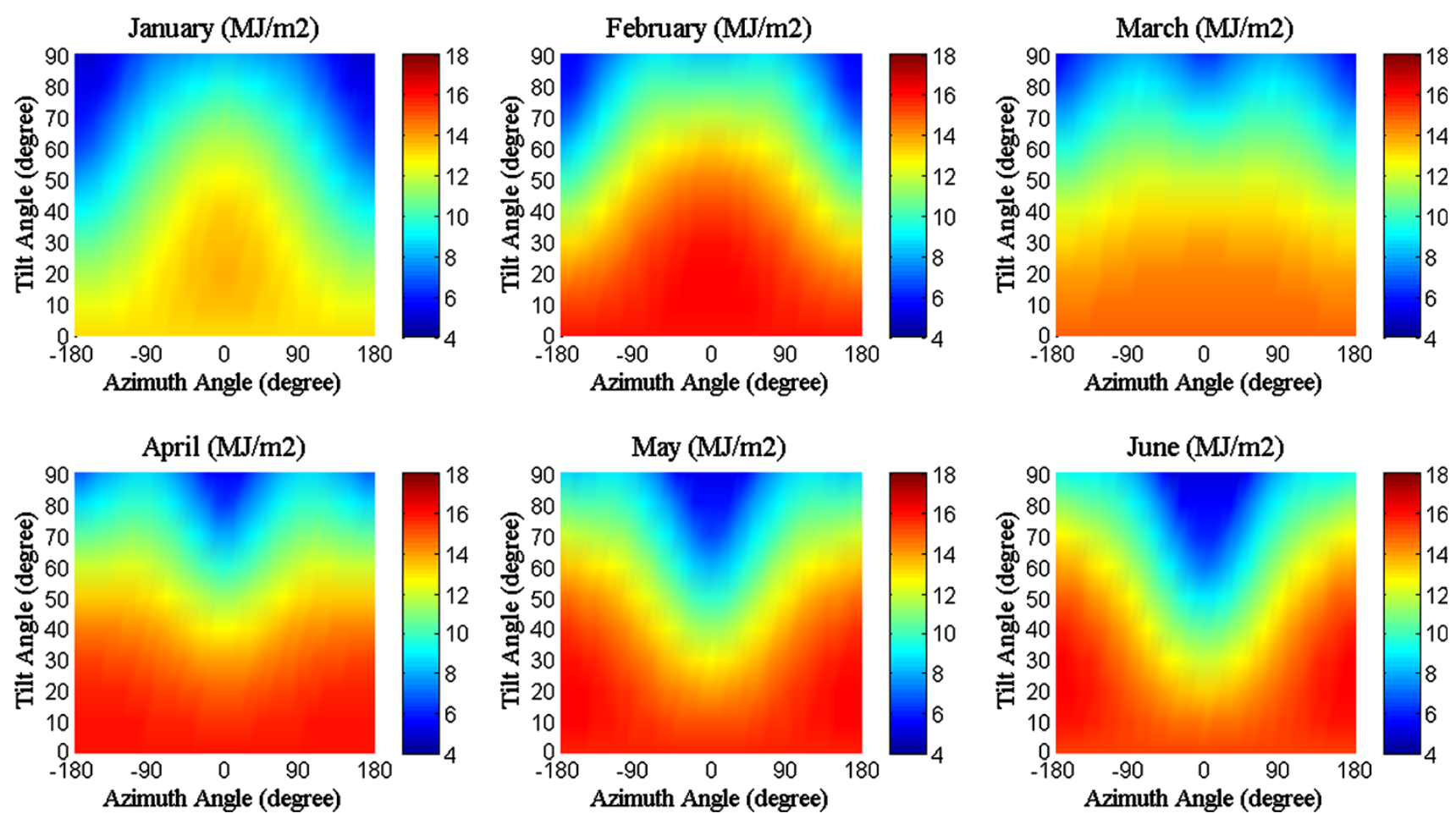

Fig. 4 Monthly average daily solar radiation at various azimuth and tilt angles from January to June
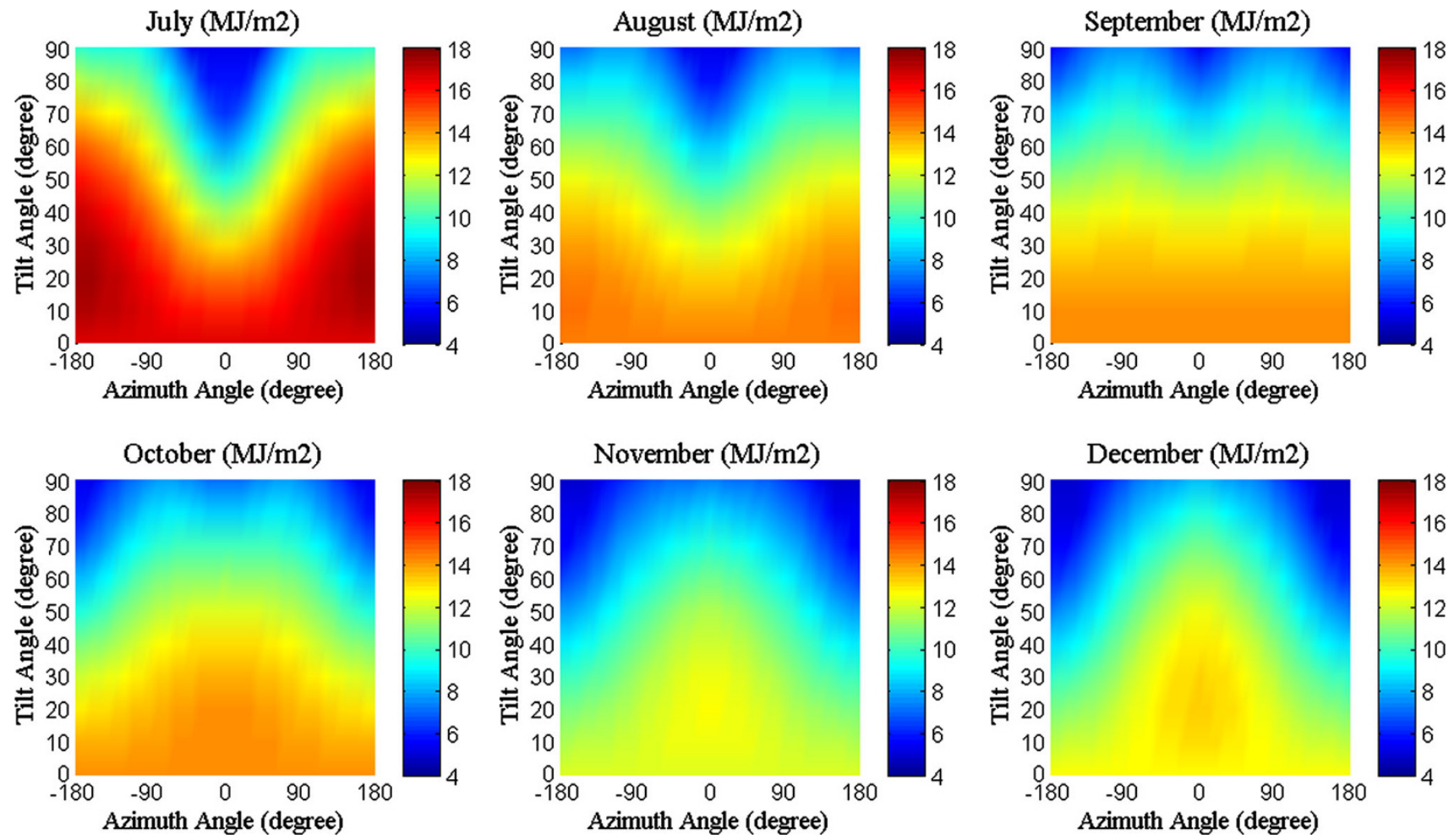

Fig. 5 Monthly average daily solar radiation at various azimuth and tilt angles from July to December 
Fig. 6 Monthly average daily solar radiation at different tilt angles for south-facing surface from January to December
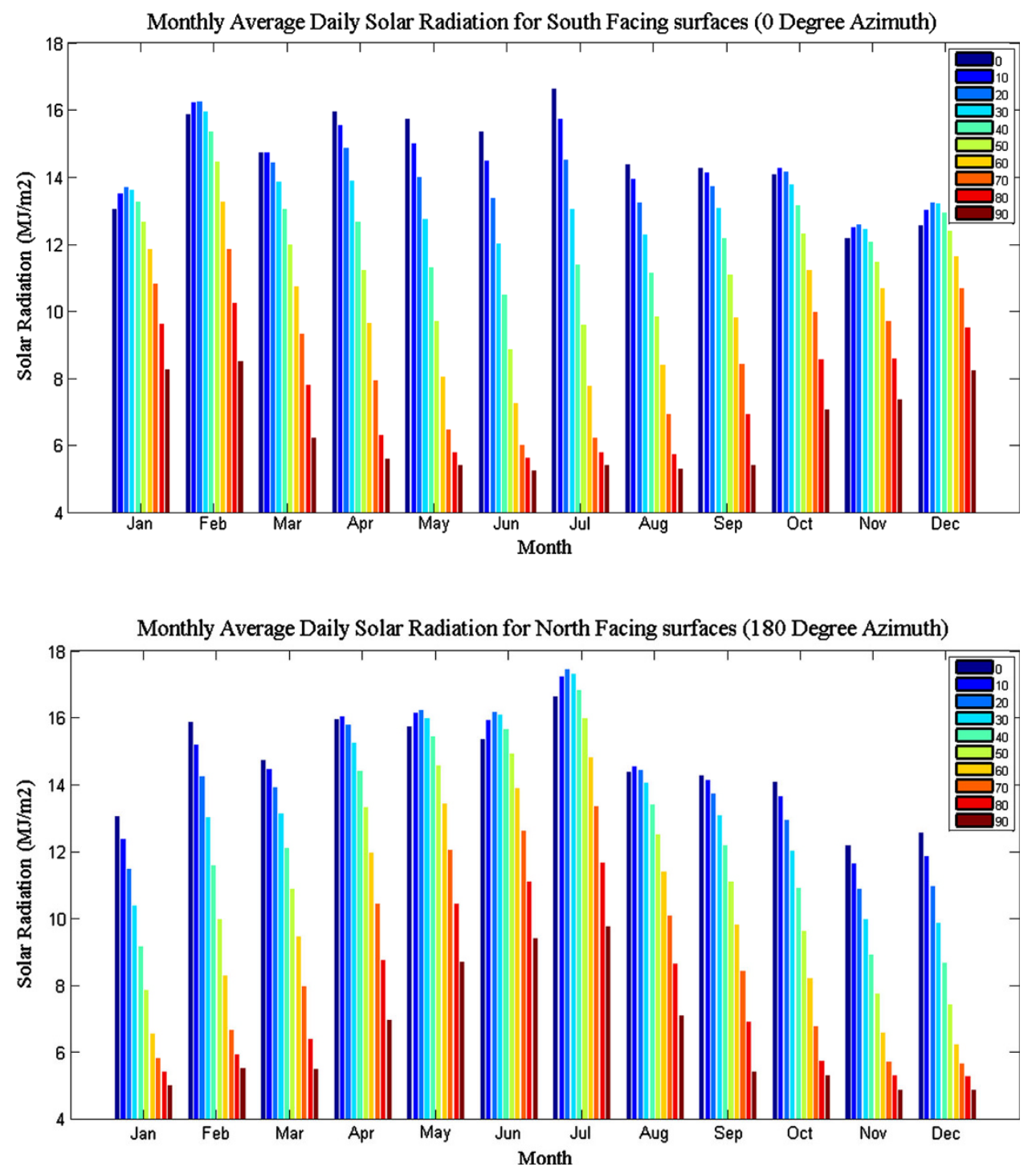

Fig. 7 Monthly average daily solar radiation at different tilt angles for north-facing surface from January to December receive a prominent amount of radiation energy during February, and north-facing absorber could gain the best during July.

Monthly, seasonal and annual optimum tilt angles

Table 1 shows the result of the monthly optimum tilt angle. The estimated monthly optimum values for south (S)- and north $(\mathrm{N})$-facing surfaces ranged from $0^{\circ}-24^{\circ}$ to $0^{\circ}-22^{\circ}$, respectively. The optimum figures were compared to the optimum tilt angles at solar noon, in which the average deviation and standard deviation were evaluated to be $1.6^{\circ}$ and $1.8^{\circ}$, respectively. In the limiting surfaces facing south and north only, one could observe that there were several months with optimum angle of $0^{\circ}$ consecutively. Due to the sun trajectory in the opposite direction of the surface planes during those periods, the optimum angle was found to be in horizontal and any opposite inclination could eventually lead to lower interception of the sunray. This constraint is necessary to reflect the fact that a building with the absorber attached on one side is ordinary static and even if it could operate responding to the environment, it is still restricted to face the same direction.

Another comparison study of the monthly optimum tilt angle was made with the correlations of Nijegorodov et al. [53], who presented a set of twelve optimum slope equations, one for each month, for any location within $\pm 60^{\circ}$ latitudes. The calculation showed that the average deviation was $5.4^{\circ}$ and the standard deviation was $6.6^{\circ}$. The Nijegorodov et al. model was noticed to yield higher optimum values than the present results. This might be caused by the nature of the formulae that was the general treatment for cloudless days without considering the specific local solar features. Since the cloud cover in the humid tropical regions can be significant, the increasing quantity of diffuse solar radiation will lower the optimum 
Table 1 Optimum tilt angles of solar absorber

\begin{tabular}{|c|c|c|c|c|c|c|c|}
\hline \multirow[t]{2}{*}{ Months } & \multicolumn{2}{|c|}{$\begin{array}{l}\text { Calculated optimum value } \\
\text { limited to south-facing } \\
\text { surfaces (S) }\end{array}$} & \multicolumn{2}{|c|}{$\begin{array}{l}\text { Calculated optimum value } \\
\text { limited to north-facing } \\
\text { surfaces }(\mathrm{N})\end{array}$} & \multirow{2}{*}{$\begin{array}{l}\text { Calculated } \\
\text { optimum } \\
\text { value } \\
\text { Tilt angle } \\
\left(^{\circ}\right)\end{array}$} & \multirow[t]{2}{*}{$\begin{array}{l}\text { Optimum tilt angles } \\
\text { at solar noon }\left(^{\circ}\right) \\
(\text { North }+ \text {; South }-)\end{array}$} & \multirow[t]{2}{*}{$\begin{array}{l}\text { Nijegorodor et al.'s } \\
\text { Correlations }\left({ }^{\circ}\right) \\
\text { (North+; South-) }\end{array}$} \\
\hline & $\begin{array}{l}\text { Tilt } \\
\text { angle } \\
\left({ }^{\circ}\right)\end{array}$ & $\begin{array}{l}\text { Monthly average } \\
\text { daily solar } \\
\text { radiation }\left(\mathrm{MJ} / \mathrm{m}^{2}\right)\end{array}$ & $\begin{array}{l}\text { Tilt } \\
\text { angle } \\
\left({ }^{\circ}\right)\end{array}$ & $\begin{array}{l}\text { Monthly average } \\
\text { daily solar } \\
\text { radiation }\left(\mathrm{MJ} / \mathrm{m}^{2}\right)\end{array}$ & & & \\
\hline January & 22 & 13.68 & 0 & 13.05 & $22(\mathrm{~S})$ & -23.9 & -31.7 \\
\hline February & 16 & 16.26 & 0 & 15.85 & $16(\mathrm{~S})$ & -16.0 & -19.9 \\
\hline March & 5 & 14.75 & 0 & 14.72 & $5(\mathrm{~S})$ & -5.4 & -7.0 \\
\hline April & 0 & 15.94 & 8 & 16.03 & $8(\mathrm{~N})$ & +6.4 & +7.0 \\
\hline May & 0 & 15.71 & 18 & 16.22 & $18(\mathrm{~N})$ & +15.8 & +21.2 \\
\hline June & 0 & 15.35 & 22 & 16.16 & $22(\mathrm{~N})$ & +20.1 & +31.4 \\
\hline July & 0 & 16.62 & 21 & 17.43 & $21(\mathrm{~N})$ & +18.2 & +27.3 \\
\hline August & 0 & 14.37 & 11 & 14.54 & $11(\mathrm{~N})$ & +10.5 & +14.1 \\
\hline September & 0 & 14.26 & 0 & 14.26 & 0 & -0.8 & -1.0 \\
\hline October & 11 & 14.25 & 0 & 14.07 & $11(\mathrm{~S})$ & -12.6 & -15.0 \\
\hline November & 19 & 12.58 & 0 & 12.17 & $19(\mathrm{~S})$ & -21.9 & -27.8 \\
\hline December & 24 & 13.25 & 0 & 12.55 & $24(\mathrm{~S})$ & -26.1 & -36.6 \\
\hline \multicolumn{5}{|c|}{ Annual optimum tilt angle } & $1.4(\mathrm{~S})$ & -3.0 & -3.2 \\
\hline
\end{tabular}

tilt angle of the absorber closer to the horizontal placement. As this is valid for all places that the horizontal plane can intercept more diffuse radiation, the present scenario could be reasoned.

The monthly optimum tilt angles for a surface facing equator in the present work was compared to a study [54] conducted in the same peninsula. A close agreement was found in which the average deviation was computed to be $0.8^{\circ}$ with small standard deviation of merely $1.4^{\circ}$.

The annual optimum tilt angle has been computed based on the estimated monthly optimum slope. Result showed that the optimum value was $1.4^{\circ}$ facing to the south (equator). The value was similar and agreed with the optimum slope presented by [39] for a latitude of $4^{\circ} 34^{\prime} \mathrm{N}$ in Malaysia. The finding was comparable to the solution estimated using the optimum tilt angles at solar noon and the Nijegorodov et al. model, which gave optimum values of $3.0^{\circ}$ and $3.2^{\circ}$, respectively. Additionally, the computed results were fairly consistent with the general rule that the yearly optimal tilt angle was about the latitude of the location facing to the equator.

The study of seasonal optimum tilt angle for maximising energy collection by the absorber has been carried out. Two seasons in 1 year were studied. The south-facing season started from 14 September until 29 March, meanwhile the north-facing season began from 30 March till 13 September. This seasonal allocation is valid as well for other regions with the similar latitude around $3^{\circ} \mathrm{N}$. Figure 8 shows the seasonal average daily solar radiation reaching on southand north-facing surfaces. It was found that the north-facing surface was exposed to higher intensity of solar radiation energy in daily average compared to south-facing plane. The results were consistent with the hypothesis posed in "Introduction". It showed a controversy to the common understanding that the south-facing surface should gain better at a northern hemisphere region. Since the investigation was performed under the influences of seasonal period and local solar radiation pattern, the outcome relied on the local solar trajectory and the measurement of solar radiation. Referring to the database, majority of the higher radiation intensity was recorded during the period of north facing, which were during April to September. Analysing the measured data, it was discovered that the horizontal average daily solar irradiation for the south- and northfacing seasons was 13.86 and $15.61 \mathrm{MJ} / \mathrm{m}^{2}$, respectively. It has shown that the received average daily local radiation level was relatively higher for the north-facing season. The simulated results have agreed to the local solar profile with similar pattern to reflect the weather trend at the site. From the figure, two polynomial equations were proposed to depict the trend of seasonal average daily solar radiation $\left(H_{s}\right)$ in function of tilt angle $\left(0 \leq \beta \leq 90^{\circ}\right)$ for a region with similar latitude under the influence of Malaysian solar pattern. The equations showed a good fit to the output.

Solving the equations $\left(\mathrm{d} H_{s} / \mathrm{d} \beta=0\right)$, the optimum tilt angles for seasonal south- and north-facing surfaces were found to be $14.43^{\circ}$ and $14.84^{\circ}$, respectively. An investigation to analyse the effect of deviation of tilt angle from the optimum value has shown that the tilt angle deviated from optimum value of $\pm 5^{\circ}$ has insignificant influence of 
Fig. 8 Seasonal average daily solar radiation for different tilt angles
Seasonal average daily solar radiation $\left(\mathrm{J} / \mathrm{m}^{2}\right)$ against tilt angle

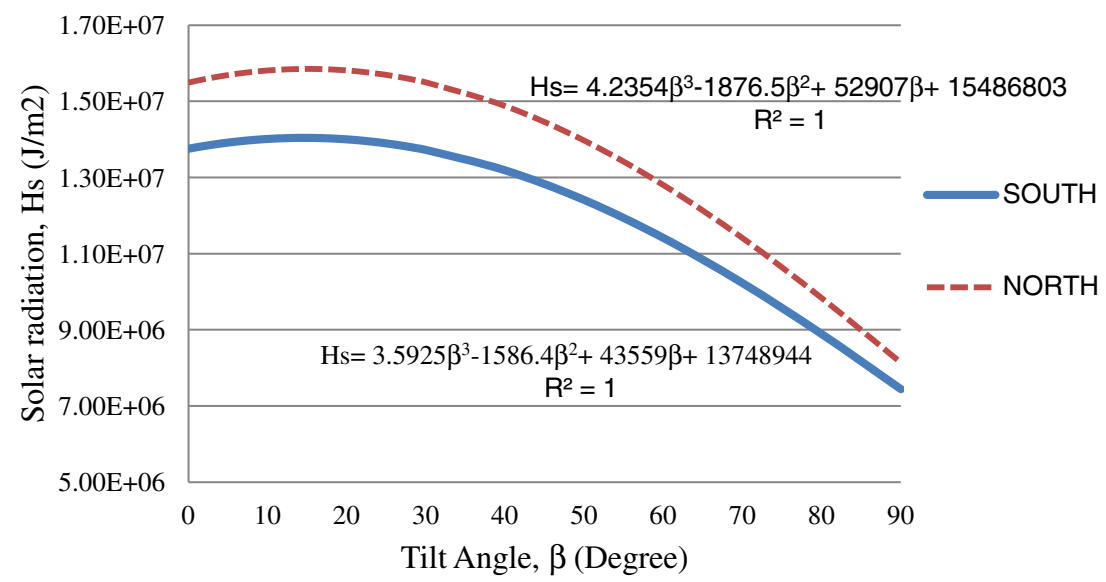

the energy interception with variation of less that $0.3 \%$ for both south- and north-facing surfaces. This indicated a tolerance of slope for optimal solar energy interception within the range from $10^{\circ}$ to $20^{\circ}$ was granted in the seasonal basis with no obvious impact. This finding has agreed to other research works addressing the similar outcome [12, 55-58]. From the results, the building facades integrated with solar harnessing feature could be oriented in the mentioned position to optimise the solar utilisation.

\section{Conclusions}

The solar radiation incident on the diversely oriented surfaces and optimal slopes for solar absorbers at low latitude region, Bangi, Malaysia were assessed. According to the obtained results, the following conclusions have been drawn.

1. Results showed that the solar radiation intensity on surfaces at different orientations and tilt angles has presented a considerably large variation. The radiation pattern followed the monthly apparent position of the sun. When the high solar radiation intensity was available at small tilt angle at $0^{\circ}$ azimuth, low solar radiation intensity was observed at large tilt angle at $180^{\circ}$ azimuth, and vice versa.

2. The surface with low tilt angles, below $20^{\circ}$, could intercept a relatively high intensity of average daily solar radiation in every month averagely throughout a year. The surfaces with horizontal placement and small angle of inclination could give a good yield in solar energy collection. Those types of orientations should be evaded if the surfaces disfavour overheating. In term of solar energy interception, a low tilt angle was relatively insensitive to the variation of azimuth angle as compared to a high tilt angle.
3. The high inclination resulted lower interception of solar radiation and thus the setup of a solar absorber on the vertical wall or high sloped surface was recommended as the secondary option at any azimuth for a low latitude region.

4. For the equator-facing surface, the three highest radiation interceptions of monthly average daily solar irradiation were discovered on July $0^{\circ}$ slope, February $10^{\circ}$ and $20^{\circ}$ slopes with radiation intensities of 16.62 , 16.21 and $16.24 \mathrm{MJ} / \mathrm{m}^{2}$, respectively. For the northfacing surface, the three highest figures were found on the same month of July at $10^{\circ}, 20^{\circ}$ and $30^{\circ}$ with values of $17.21,17.43$ and $17.29 \mathrm{MJ} / \mathrm{m}^{2}$, respectively.

5. The monthly optimum tilt angle changed throughout the year, ranging from $-24^{\circ}$ (south facing) to $+22^{\circ}$ (north facing).

6. A comparison study of the monthly optimum tilt angle was made with the optimum tilt angle at solar noon and the Nijegorodov et al. model. For the former comparison, the average deviation was about $1.6^{\circ}$ and the standard deviation was evaluated to be $1.8^{\circ}$. The latter comparison showed that the average deviation was $5.4^{\circ}$ and the standard deviation was $6.6^{\circ}$. The present results indicated that the simple method of finding optimum tilt angle at solar noon could be suitably used to estimate the monthly optimum tilt angle for low latitude region.

7. The calculated annual optimum tilt angle was $1.4^{\circ}$ facing to the equator, which was close to the results by the optimum tilt angle at solar noon and the Nijegorodov et al. model.

8. The analysis of the seasonal average daily solar radiation discovered that the north-facing surface was exposed to higher intensity of solar radiation energy compared to south-facing plane. The simulated results have agreed to the local solar profile with similar 
pattern to reflect the weather trend at the site. The optimum angles for seasonal south- and north-facing surfaces were determined to be $14.43^{\circ}$ and $14.84^{\circ}$, respectively. It was found that the slope deviation from optimum value of $\pm 5^{\circ}$ has insignificant influence of the energy interception with variation of less that $0.3 \%$ for both south- and north-facing surfaces. Therefore, the tolerance of tilt angle for optimal solar energy interception within the range of $10^{\circ}$ to $20^{\circ}$ was acceptable in the seasonal basis.

9. The above results could serve as the references for the solar application in buildings of the West Coast of Peninsular Malaysia.

Acknowledgments The first author would like to acknowledge the Ministry of Higher Education Malaysia for the MyBrain15-MyPhD scholarship.

Conflict of interest The authors declare that they have no competing interests.

Author contribution KMN carried out the computational simulation and drafted the manuscript. NMA checked the analysis and revised the manuscript. OI and MZAAK both provided technical guidance and critical review of the manuscript. All authors read and approved the final manuscript.

Open Access This article is distributed under the terms of the Creative Commons Attribution License which permits any use, distribution, and reproduction in any medium, provided the original author(s) and the source are credited.

\section{References}

1. Ibrahim, A., Othman, M.Y., Ruslan, M.H., Mat, S., Sopian, K.: Recent advances in flat plate photovoltaic/thermal (PV/T) solar collectors. Renew. Sustain. Ener. Rev. 15(1), 352-365 (2011)

2. Ramirez-Stefanou, M., Mallick, T., Smyth, M., Mondol, J.D., Zacharopoulos, A., Hyde, T.J.: Characterisation of a line-axis solar thermal collector for building facade integration. In: Howlett, R., Jain, L.C., Lee, S.H. (eds.) Sustainability in energy and buildings. Smart innovation, systems and technologies, vol. 7, pp. 277-287. Springer, Berlin (2011)

3. Liu, B.Y.H., Jordan, R.C.: Daily insolation on surfaces tilted towards the equator. ASHRAE J. 3, 53-59 (1961)

4. Klein, S.A.: Calculation of monthly average insolation on tilted surfaces. Sol. Ener. 19(4), 325-329 (1977)

5. Temps, R.C., Coulson, K.L.: Solar radiation incident upon slopes of different orientations. Sol. Ener. 19(2), 179-184 (1977)

6. Klucher, T.M.: Evaluation of models to predict insolation on tilted surfaces. Sol. Ener. 23(2), 111-114 (1979)

7. Hay, J.E.: Calculation of monthly mean solar radiation for horizontal and inclined surfaces. Sol. Ener. 23(4), 301-307 (1979)

8. Klein, S.A., Theilacker, J.C.: An algorithm for calculating monthly-average radiation on inclined surfaces. J. Sol. Ener. Eng. 103(1), 29-33 (1981)

9. Perez, R., Seals, R., Ineichen, P., Stewart, R., Menicucci, D.: A new simplified version of the perez diffuse irradiance model for tilted surfaces. Sol. Ener. 39(3), 221-231 (1987)
10. Duffie, J.A., Beckman, W.A.: Solar engineering of thermal processes, 3rd edn. John Wiley \& Sons Inc, USA (2006)

11. Chow, T.T., Chan, A.L.S.: Numerical study of desirable solarcollector orientations for the coastal region of South China. Appl. Ener. 79(3), 249-260 (2004)

12. Elminir, H.K., Ghitas, A.E., El-Hussainy, F., Hamid, R., Beheary, M.M., Abdel-Moneim, K.M.: Optimum solar flat-plate collector slope: case study for Helwan, Egypt. Ener. Conv. Man. 47(5), 624-637 (2006)

13. Yang, H., Lu, L.: The optimum tilt angles and orientations of PV claddings for building-integrated photovoltaic (BIPV) applications. J. Sol. Ener. Eng. 129(2), 253-255 (2005)

14. Pandey, C.K., Katiyar, A.K.: A note on diffuse solar radiation on a tilted surface. Energy 34(11), 1764-1769 (2009)

15. El-Sebaii, A.A., Al-Hazmi, F.S., Al-Ghamdi, A.A., Yaghmour, S.J.: Global, direct and diffuse solar radiation on horizontal and tilted surfaces in Jeddah, Saudi Arabia. Appl. Ener. 87(2), 568-576 (2010)

16. Jafarkazemi, F., Saadabadi, S.A.: Optimum tilt angle and orientation of solar surfaces in Abu Dhabi, UAE. Renew. Ener. 56, 44-49 (2013)

17. Jafarkazemi, F., Ali Saadabadi, S., Pasdarshahri, H.: The optimum tilt angle for flat-plate solar collectors in Iran. J. Renew. Sust. Ener. 4(1) (2012)

18. Yadav, A.K., Chandel, S.S.: Tilt angle optimization to maximize incident solar radiation: a review. Renew. Sustain. Ener. Rev. 23, 503-513 (2013)

19. Celik, A.N., Muneer, T.: Neural network based method for conversion of solar radiation data. Ener. Convers. Man. 67, 117-124 (2013)

20. Khatib, T., Mohamed, A., Mahmoud, M., Sopian, K.: An assessment of diffuse solar energy models in terms of estimation accuracy. Ener. Procedia 14, 2066-2074 (2012)

21. Talebizadeh, P., Mehrabian, M.A., Abdolzadeh, M.: Prediction of the optimum slope and surface azimuth angles using the genetic algorithm. Ener. Build. 43(11), 2998-3005 (2011)

22. Behrang, M.A., Assareh, E., Noghrehabadi, A.R., Ghanbarzadeh, A.: New sunshine-based models for predicting global solar radiation using PSO (particle swarm optimization) technique. Energy 36(5), 3036-3049 (2011)

23. Yaow-Ming, C., Chien-Hsing, L., Hsu-Chin, W.: Calculation of the optimum installation angle for fixed solar-cell panels based on the genetic algorithm and the simulated-annealing method. Ener. Conv. IEEE Trans. 20(2), 467-473 (2005)

24. Mekhilef, S., Safari, A., Mustaffa, W.E.S., Saidur, R., Omar, R., Younis, M.A.A.: Solar energy in Malaysia: current state and prospects. Renew. Sustain. Ener. Rev. 16(1), 386-396 (2012)

25. Chuah, D.G.S., Lee, S.L.: Solar radiation estimates in Malaysia. Sol. Ener. 26(1), 33-40 (1981)

26. Chuah, D.G.S., Lee, S.L.: Solar radiation in peninsular Malaysia: statistical presentations. Ener. Conv. Man. 22(1), 71-84 (1982)

27. Childs, R.E., Chuah, D.G.S., Lee, S.L., Tan, K.C.: Analysis of solar radiation data using cubic splines. Sol. Ener. 32(5), 643-653 (1984)

28. Sopian, K., Othman, M.Y.H.: Estimates of monthly average daily global solar radiation in Malaysia. Renew. Ener. 2(3), 319-325 (1992)

29. Othman, M.Y.H., Sopian, K., Yatim, B., Dalimin, M.N.: Diurnal pattern of global solar radiation in the tropics: a case study in Malaysia. Renew. Ener. 3(6-7), 741-745 (1993)

30. Sulaiman, M.Y., Hlaing oo, W.M., Wahab, M.A., Sulaiman, Z.A.: Analysis of residuals in daily solar radiation time series. Renew. Ener. 11(1), 97-105 (1997)

31. Sulaiman, M.Y., Hlaing Oo, W.M., Abd, Wahab M., Zakaria, A.: Application of beta distribution model to Malaysian sunshine data. Renew. Ener. 18(4), 573-579 (1999) 
32. Rahman, I.A., Dewsbury, J.: Selection of typical weather data (test reference years) for Subang, Malaysia. Build. Environ. 42(10), 3636-3641 (2007)

33. Azhari, A.W., Sopian, K., Zaharim, A.: New approach for predicting solar radiation in tropical environment using satellite images: case study of Malaysia. WSEAS Trans. Environ. Dev. 4(4), 373-378 (2008)

34. Daut, I., Irwanto, M., Irwan, Y.M., Gomesh, N., Ahmad, N.S.: Combination of Hargreaves method and linear regression as a new method to estimate solar radiation in Perlis, Northern Malaysia. Sol. Ener. 85(11), 2871-2880 (2011)

35. Wan Nik, W.B., Ibrahim, M.Z., Samo, K.B., Muzathik, A.M.: Monthly mean hourly global solar radiation estimation. Sol. Ener. 86(1), 379-387 (2012)

36. Ng, K.M., Adam, N.M., Azmi, B.Z., Wahab, M.A., Sulaiman, M.Y.: Field study of solar bowl under Malaysian tropical climate. WSEAS Trans. Environ. Dev. 8(2), 48-59 (2012)

37. Eltbaakh, Y.A., Ruslan, M.H., Alghoul, M.A., Othman, M.Y., Sopian, K.: Measurements of spectral-band solar irradiance in Bangi, Malaysia. Sol. Ener. 89, 62-80 (2013)

38. Bari, S.: Optimum slope angle and orientation of solar collectors for different periods of possible utilization. Ener. Conv. Man. 41(8), 855-860 (2000)

39. Bari, S.: Optimum orientation of domestic solar water heaters for the low latitude countries. Ener. Conv. Man. 42(10), 1205-1214 (2001)

40. Yakup, M.A.b.H.M., Malik, A.Q.: Optimum tilt angle and orientation for solar collector in Brunei Darussalam. Renew. Ener. 24(2), 223-234 (2001)

41. Cronemberger, J., Caamano-Martin, E., Sanchez, S.V.: Assessing the solar irradiation potential for solar photovoltaic applications in buildings at low latitudes: making the case for Brazil. Ener. Build. 55, 264-272 (2012)

42. Idowu, O., Olarenwaju, O., Ifedayo, O.: Determination of optimum tilt angles for solar collectors in low-latitude tropical region. Intern. J. Ener. Environ. Eng. 4, 29 (2013)

43. Nieuwoudt, M.N., Mathews, E.H.: A mobile solar water heater for rural housing in Southern Africa. Build. Environ. 40(9), 1217-1234 (2005)

44. Kern, J., Harris, I.: On the optimum tilt of a solar collector. Sol. Ener. 17(2), 97-102 (1975)
45. Panchal, H., Shah, P.: Investigation on solar stills having floating plates. Intern. J. Ener. Environ. Eng. 3, 8 (2012)

46. Pardhi, C., Bhagoria, J.: Development and performance evaluation of mixed-mode solar dryer with forced convection. Intern. J. Ener. Environ. Eng. 4, 23 (2013)

47. Sharma, P., Harinarayana, T.: Solar energy generation potential along national highways. Intern. J. Ener. Environ. Eng. 4, 16 (2013)

48. Roohollahi, E., Mehrabian, M.A., Abdolzadeh, M.: Prediction of solar energy gain on 3D geometries. Ener. Build. 62, 315-322 (2013)

49. Cooper, P.I.: The absorption of radiation in solar stills. Sol. Ener. 12(3), 333-346 (1969)

50. Gueymard, C.A.: Direct and indirect uncertainties in the prediction of tilted irradiance for solar engineering applications. Sol. Ener. 83(3), 432-444 (2009)

51. ASHRAE: ASHRAE handbook-fundamental (I-P Edition), p. 2009. The American Society of Heating, Refrigerating and AirConditioning Engineers, Boston (2009)

52. Erbs, D.G., Klein, S.A., Duffie, J.A.: Estimation of the diffuse radiation fraction for hourly, daily and monthly-average global radiation. Sol. Ener. 28(4), 293-302 (1982)

53. Nijegorodov, N., Devan, K.R.S., Jain, P.K., Carlsson, S.: Atmospheric transmittance models and an analytical method to predict the optimum slope of an absorber plate, variously oriented at any latitude. Renew. Ener. 4(5), 529-543 (1994)

54. Khatib, T., Mohamed, A., Sopian, K.: Optimization of a PV/wind micro-grid for rural housing electrification using a hybrid iterative/genetic algorithm: case study of Kuala Terengganu, Malaysia. Ener. Build. 47, 321-331 (2012)

55. Felske, J.D.: The effect of off-south orientation on the performance of flat-plate solar collectors. Sol. Ener. 20(1), 29-36 (1978)

56. Iqbal, M.: Optimum collector slope for residential heating in adverse climates. Sol. Ener. 22(1), 77-79 (1979)

57. Saraf, G.R., Hamad, F.A.W.: Optimum tilt angle for a flat plate solar collector. Ener. Conv. Man. 28(2), 185-191 (1988)

58. Elsayed, M.M.: Optimum orientation of absorber plates. Sol. Ener. 42(2), 89-102 (1989) 